\title{
Analysis of Adrenergic Regulation of Melatonin Synthesis in Siberian Hamster Pineal Emphasizes the Role of HIOMT
}

\author{
R.M. Ceinos ${ }^{a}$ M. Chansard ${ }^{b}$ F. Revel ${ }^{b}$ C. Calgari ${ }^{b} \quad$ J.M. Míguez ${ }^{a}$ \\ V. Simonneaux ${ }^{b}$ \\ a Laboratorio de Fisiología Animal, Facultad de Biología, Universidad de Vigo, Vigo, Spain; \\ bNeurobiologie des Rythmes, UMR-CNRS 7518, Université Louis-Pasteur, Strasbourg, France
}

\section{Key Words}

Adrenergic receptors . Norepinephrine Pineal gland .

Arylalkylamine $\mathrm{N}$-acetyltransferase AA-NAT .

Hydroxyindole-O-methyltransferase HIOMT .

Melatonin - Siberian hamster $\cdot$ Photoperiod

\begin{abstract}
Seasonal variations of environmental factors are translated into annual fluctuations in synthesis and release of melatonin, which in turn acts as a neuroendocrine messenger for the synchronization of annual functions. So far, most studies performed to understand the regulation of melatonin synthesis have used the non seasonal laboratory rat. It was demonstrated that nocturnal melatonin synthesis depends on $\alpha$ - and $\beta$-adrenergic activation of the enzyme arylalkylamine $\mathrm{N}$-acetyltransferase (AANAT). In this study, we investigated the mechanisms of melatonin synthesis in the Siberian hamster, a seasonal species with marked photoperiodic variation in melatonin peak duration and amplitude. A $\beta$-adrenergic receptor agonist alone markedly stimulated AA-NAT activity and melatonin synthesis and release. An $\alpha$-adrenergic receptor agonist, while having no effect per se, potentiated the $\beta$-adrenergic stimulation of AA-NAT activity
\end{abstract}

\section{KARGER}

Fax +41613061234

E-Mail karger@karger.ch

www.karger.com
(C) 2004 S. Karger AG, Basel

$1424-862 X / 04 / 0136-0308 \$ 21.00 / 0$

Accessible online at:

www. karger.com/nsg both in vitro and in vivo. Strikingly, the potentiation of AA-NAT activity did not result in a potentiation of melatonin synthesis, suggesting that the rate of melatonin production is limited downstream in the metabolic pathway, most probably at the level of hydroxyindole-Omethyltransferase (HIOMT). HIOMT presented a constitutively high activity that was not acutely (within hours) stimulated by $\beta$-adrenergic agonist, but was rather upregulated by chronic application of the agonist. This long-term $\beta$-adrenergic regulation may explain the reported large photoperiodic variation of HIOMT activity that drives the photoperiodic variation in melatonin peak.

Copyright $@ 2004$ S. Karger AG, Basel

\section{Introduction}

Melatonin from the pineal gland is synthesized and released with both a daily rhythm, with high nocturnal levels, and an annual rhythm with seasonal modification of the nocturnal peak [1]. The reproducibility of these rhythms is critical for the organism to anticipate and synchronize most of its cycling functions with the daily and seasonal variations of its environment. The seasonal

Dr. Valérie Simonneaux

UMR CNRS/ULP 7518 Neurobiologie des Rythmes

12, rue de l'Université, FR-67000 Strasbourg (France)

Tel. +33 390240501, Fax +33390240528

E-Mail simonneaux@neurochem.u-strasbg.fr 
variation in the nocturnal peak of melatonin is the endocrine link for the synchronization of reproductive functions with the seasons in most species [1-3].

Although the laboratory rat is not a seasonal species, most of our knowledge on the regulation of melatonin has been obtained from this rodent [ 4 for review]. The rat pineal gland is massively innervated by sympathetic fibers whose activity is indirectly controlled by the endogenous biological clock located in the suprachiasmatic nuclei of the hypothalamus [5-7, 4 for review]. These fibers primarily contain and release norepinephrine (NE) [8], the essential neurotransmitter involved in the nocturnal stimulation of melatonin synthesis [9, 10]. Melatonin is synthesized from serotonin following acetylation by arylalkylamine-N-acetyltransferase (AA-NAT; EC 2.3.1.87) and methylation by hydroxyindole-O-methyltransferase (HIOMT; EC 2.1.1.4), then immediately released into the blood stream [11]. In all species studied so far, AA-NAT activity is markedly increased at night making it the 'melatonin rhythm-generating enzyme' [12]. HIOMT activity, by contrast, remains quite stable over the day/night cycle but displays photoperiodic variation, being higher in short photoperiod [13, 14].

In the rat pineal gland, NE binds to two kinds of membrane receptors: $\alpha_{1}$ - (positively coupled to phospholipase C) and $\beta_{1^{-}}$(positively coupled to adenylate cyclase) adrenergic receptors (AR). Activation of $\beta_{1}$-AR alone increases cAMP levels which, in turn, activates a cAMP-dependent protein kinase (PKA). PKA induces a large increase in AA-NAT activity using several intracellular pathways: increase in Aa-nat gene expression via CREB phosphorylation, direct phosphorylation of AA-NAT protein and protection from proteasomal degradation $[4,12$ for review]. The Hiomt gene expression is constitutively high but yet marginally increased following $\beta_{1}$-AR induced PKA activation, but enzyme activity remains unchanged $[13,16]$. On the other hand, binding to $\alpha_{1}$-AR increases $\mathrm{IP}_{3}$ and $\left[\mathrm{Ca}^{2+}\right]$ concentrations and activates a calciumdependent protein kinase. This event has no effect per se on cAMP, but markedly increases the $\beta_{1}$-AR activated cAMP/PKA/AA-NAT pathway [17-19]. Nocturnal release of NE, therefore, mainly induces a cAMP/PKAdependent activation of AA-NAT that drives the nocturnal increase in melatonin synthesis and release.

In most species, seasonal modification in night length results in significant adjustments in duration and amplitude of the nocturnal peak of melatonin [1,20]. Seasonal modification of melatonin peak duration appears to be sufficient for transmitting the photoperiodic message and thus for synchronizing annual functions such as reproduc- tion or hibernation $[1,21,22]$. However, annual variation in the amplitude of the nocturnal peak of melatonin is also an important parameter for transmission of seasonal information [23 for review].

Among seasonal species, the Siberian hamster displays marked variation in melatonin peak duration and amplitude [24-26], making this species a valuable model to study the mechanisms underlying the seasonal regulation of melatonin synthesis. An earlier study reported that night-time administration of adrenergic antagonists inhibited melatonin synthesis, indicating the involvement of NE in the nocturnal stimulation of melatonin [27]. In the present study, we used both in vitro and in vivo approaches to analyze the respective role of $\alpha$ - and $\beta$-AR in the regulation of AA-NAT and HIOMT activities and, in turn, in melatonin production.

\section{Material and Methods}

\section{Animals}

Djungarian hamsters (Phodopus sungorus) were born and raised in our breeding colony. They were kept under $16 \mathrm{~h}$ light ( $200 \mathrm{~lx}$ intensity)/8 h dark ( $2 \mathrm{~lx}$ dim red light) lighting schedule (with lights on from 5 to $21 \mathrm{~h}$ ) at $22 \pm 1{ }^{\circ} \mathrm{C}$ with food and water available ad libitum. Eighteen-month-old animals were used for the in vivo experiments, 2- to 3-month-old males and females were used for the in vitro experiments.

All experiments were performed in accordance with the National Institutes of Health 'Principles of Laboratory Animal Care' (National Institutes of Health publication 86-23, revised 1985) and French National laws.

\section{Experimental Protocols}

In vitro Experiments: Effect of $\alpha / \beta$-Adrenergic Agonists on Melatonin Synthesis. Hamsters were sacrificed $4 \mathrm{~h}$ after lights on. The pineal glands were removed and transferred to culture medium containing DMEM (Dulbecco's modified Eagle medium, Sigma) supplemented with HEPES $10 \mathrm{~m} M, \mathrm{NaHCO}_{3} 44 \mathrm{~m} M$ and gentamycin $(0.04 \mathrm{mg} / \mathrm{ml})$ for incubation at $37^{\circ} \mathrm{C}$ under a water-saturated $95-5 \%$ air- $\mathrm{CO}_{2}$ atmosphere. For short-term experiments, pineal glands were preincubated for $2 \mathrm{~h}$ (preliminary tests showed that this time was enough to get a constant low level of melatonin production), and then transferred to a fresh medium with/without various concentrations of the $\beta$-adrenergic agonist isoproterenol (ISO, Sigma, St Louis, Mo., USA) and/or the $\alpha$-adrenergic agonist phenylephrine (PHE, Sigma) for $5 \mathrm{~h}$. For long-term experiments, pineal glands were preincubated for $2 \mathrm{~h}$, then transferred to a fresh medium with/without $10 \mu M$ ISO which was renewed at the same time point over the next 4 following days, and finally stimulated with $1 \mathrm{~m} M$ dibutyril cAMP for $5 \mathrm{~h}$. At the end of each experiment, pineal glands were removed and immediately processed for enzymatic assays; culture media were collected and kept frozen $\left(-20^{\circ} \mathrm{C}\right)$ until melatonin assay.

In vivo Experiments: Effect of $\alpha / \beta$-Adrenergic Ligands on Melatonin Synthesis. In order to determine the putative role of $\alpha$ - and $\beta$-AR on the in vivo melatonin synthesis, three groups of hamsters 
were injected intraperitoneally (i.p.) at daytime $(11 \mathrm{~h})$ with either ISO ( $5 \mathrm{mg} / \mathrm{kg})$, PHE ( $5 \mathrm{mg} / \mathrm{kg}$ ) or vehicle (Ringer) and sacrificed $3 \mathrm{~h}$ after treatment.

In order to determine which ARs are involved in the nocturnal elevation of AA-NAT activity and melatonin content in the pineal gland, three groups of hamsters were injected i.p. at night $(23 \mathrm{~h})$ either with an $\alpha$-adrenergic antagonist, prazosine (PRAZ, $20 \mathrm{mg} / \mathrm{kg}$, Sigma), a $\beta$-adrenergic antagonist, propanolol (PROP, $20 \mathrm{mg} / \mathrm{kg}$, Sig$\mathrm{ma}$ ), or vehicle (Ringer with $25 \%$ dimethylsulfoxide). Hamsters were sacrificed $3 \mathrm{~h}$ after injection under a dim red light. For comparison, untreated animals were killed during the daytime $(11 \mathrm{~h})$.

After sacrifice, the pineal glands were quickly removed, frozen in liquid nitrogen and stored at $-80^{\circ} \mathrm{C}$ until enzymatic and melatonin assays.

\section{Melatonin and Enzyme Activity Assays}

AA-NAT Activity. AA-NAT activity was assayed in pineal homogenates according to Garidou et al. [29] with some modification. Each pineal was sonicated in $100 \mu 10.05 M$ phosphate buffer (pH 6.6) containing $0.35 \mathrm{~m} M$ acetyl-CoA (Sigma). Briefly, $70 \mu \mathrm{l}$ tissue homogenate was incubated in the presence of $7 \mu \mathrm{l}\left[{ }^{14} \mathrm{C}\right]$ acetyl-coA $(44.1 \mathrm{mCi} / \mathrm{mmol}$; NEN-Dupont; final specific activity $5.06 \mu \mathrm{Ci} /$ $\mu \mathrm{mol})$ and $17.5 \mu \mathrm{l}$ tryptamine $(80 \mathrm{~m} M$, Sigma) in a final volume of $140 \mu \mathrm{l}$, for $20 \mathrm{~min}$ at $37^{\circ} \mathrm{C}$. Addition of $1 \mathrm{ml}$ ice-cold water saturated chloroform stopped the reaction and allowed 5-hydroxytryptamine extraction. After evaporation of $800 \mu \mathrm{l}$ chloroform, the residue was resuspended in $3.5 \mathrm{ml}$ scintillation medium and the radioactivity was counted.

HIOMT Activity. HIOMT activity was assayed as described previously [30]. Briefly, each pineal gland was sonicated in $100 \mu \mathrm{l}$ sodium phosphate buffer $(0.05 \mathrm{M}$; $\mathrm{pH} 7.9)$. An aliquot of $50 \mu \mathrm{l}$ of pineal homogenate was incubated for $30 \mathrm{~min}$ at $37^{\circ} \mathrm{C}$ in the presence $1 \mu \mathrm{l}$ $N$-acetylserotonin $\left(1 \mathrm{~m} M\right.$, Sigma) and $12.9 \mu \mathrm{l} \mathrm{S}$-adenosyl- $L$ - $\left[{ }^{14} \mathrm{C}\right]-$ methionine (43.8 $\mu M$; NEN-Dupont; final specific activity $52.7 \mathrm{Ci} /$ mol) in a final volume of $100 \mu$ l. The reaction was stopped by addition of $200 \mu \mathrm{l}$ of sodium borate buffer $(12.5 \mathrm{mM} ; \mathrm{pH} 10)$ and $1 \mathrm{ml}$ ice-cold water saturated chloroform. After evaporation of $800 \mu \mathrm{l}$ chloroform, the residue was resuspended in $3.5 \mathrm{ml}$ scintillation medium and the radioactivity was counted.

Melatonin Assay. Melatonin was measured by radio-immunoassay as follows. Tissue homogenate $(10 \mu \mathrm{l})$ or culture medium $(20 \mu \mathrm{l})$ was incubated in the presence of rabbit serum (R 19540, Institut National de la Recherche Agronomique (INRA), Nouzilly, France) at a final dilution of $1 / 20,000$ and laboratory-made $\left[{ }^{125} \mathrm{I}\right]$ melatonin as radiolabel overnight at $4{ }^{\circ} \mathrm{C}$. Sheep anti-rabbit antiserum (INRA) was used to separate the bound and free ligand. This assay was validated in the Siberian hamster by Miguez et al. [25].

\section{Analysis of Day and Night Aa-nat Gene Expression}

$c D N A$ Isolation and Sequencing. Total RNA was extracted from 10 pineal glands sampled at midnight by using RNAble (Eurobio, France). $1 \mu \mathrm{g}$ of total RNA was reverse-transcribed in a reaction volume of $10 \mu \mathrm{l}$ containing $2.5 \mu \mathrm{M}$ of oligodT, $250 \mu \mathrm{M}$ of each dNTP (Eurobio), 200 units of M-MLV reverse transcriptase (Promega, France), $50 \mu M$ Tris- $\mathrm{HCl}(\mathrm{pH} 7.5), 75 \mathrm{~m} M \mathrm{KCl}, 3 \mathrm{~m} M \mathrm{MgCl}_{2}$, $10 \mathrm{~m} M$ DTT and 10 units of RNasin ribonuclease inhibitor (Promega). Samples were incubated for $60 \mathrm{~min}$ at $37^{\circ} \mathrm{C}$ then $5 \mathrm{~min}$ at $95^{\circ} \mathrm{C}$. PCR reactions were carried out with $1 \mu \mathrm{cDNAs}$ in presence of $1 \mu \mathrm{M}$ of both upstream and downstream oligonucleotide primers, $100 \mu M$ of each dNTP, 1 unit of Taq DNA polymerase (Eurobio) in a specific reaction buffer according to manufacturer's protocol. The PCR conditions were 35 cycles at $94^{\circ} \mathrm{C} 1 \mathrm{~min} ; 54^{\circ} \mathrm{C} 1 \mathrm{~min} ; 72^{\circ} \mathrm{C} 1 \mathrm{~min}$ followed by a $20 \mathrm{~min}$ extension at $72^{\circ} \mathrm{C}$. cDNAs were amplified with universal primers designed from rat, golden hamster and sheep sequences. A 469-bp amplified product was purified, blunt-ended, ligated into the pCR-Script Amp SK(+) cloning vector according to manufacturer's protocol (Stratagene, USA) and then introduced into XL10-Gold supercompetent cells. After purification of the plasmid (QIAfilter plasmid kit, Qiagen, France), both strands of cDNAs were sequenced.

In situ Hybridization. Brain with pineal attached was sampled from midday and midnight hamsters and frozen in $-30^{\circ} \mathrm{C}$ isopentane. Serial coronal sections $(20 \mu M)$ of the pineal gland were cut and treated for in situ hybridization as previously described [28-29]. Sense and antisense ${ }^{35}$ S-labelled $\mathrm{Aa}$-nat riboprobe were incubated on pineal sections at $54^{\circ} \mathrm{C}$ overnight then washed out at high stringency $[28,29]$. Sections were exposed to X-ray films (BioMax MS-1, Kodak) for 4 days.

\section{Data Analyses}

AA-NAT and HIOMT activities are expressed in picomoles per hour per pineal gland. Melatonin content is given in nanograms per pineal gland (in vivo experiment) or nanograms released per $5 \mathrm{~h}$ per gland (in vitro experiment). All data are given as means \pm SEM of $\mathrm{n}=4$ replicates (in vitro studies) or $\mathrm{n}=5$ animals (in vivo studies). Statistical analyses were performed using an ANOVA, with subsequent Fisher LSD test, with $\mathrm{p}<0.05\left(^{*}\right)$ as the criterion of significance.

\section{Results}

\section{Day/Night Variation of Pineal Activity}

We previously reported that the nocturnal increase in melatonin synthesis in the Siberian hamster pineal is due, like in other mammals, to an increase in AA-NAT but not HIOMT activity, the latter being similarly high at day and night [30]. To check whether AA-NAT activation results from transcriptional mechanisms, like in other rodents [4], we cloned part of the Siberian hamster Aa-nat gene and analyzed its day/night expression. The 469-bp amplified cDNA fragment (NCBI accession number AY278676) showed a high sequence homology with previous Aa-nat cloned from the Syrian hamster (93\%), mouse $(91 \%)$, rat $(90 \%)$, bovine $(86 \%)$ and human $(84 \%)$ pineal gland. The identity of the cloned fragment was confirmed by the highly specific hybridization of the corresponding antisense riboprobe in the Siberian pineal gland (fig. 1). Day/night comparison of the hybridization signal showed that Aa-nat mRNA level is strong at night and barely detected during the day.

\section{Adrenergic Regulation of Melatonin Synthesis in vitro}

In order to determine the characteristics of the adrenergic regulation of AA-NAT and HIOMT activities and 
Fig. 1. Day/night expression of Aa-nat gene in the pineal of Siberian hamster. Sections of Siberian hamster brain sampled during the day $(12 \mathrm{~h})$ or night $(1 \mathrm{~h})$ were hybridized with ${ }^{35}$ S-labelled antisense $\mathrm{Aa}$-nat riboprobe and expose to $\mathrm{X}$-ray film for 4 days.
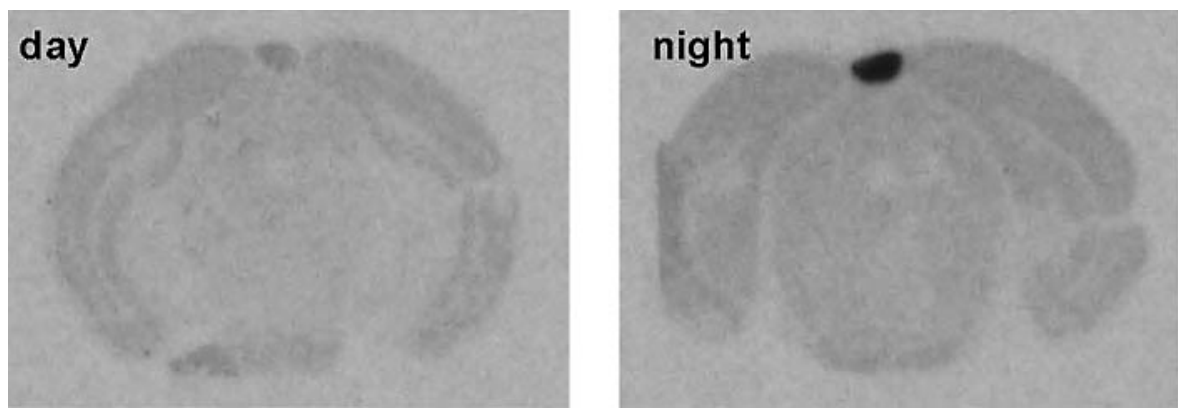

Pineal AA-NAT activity (pmol/gland/h)

Released Melatonin

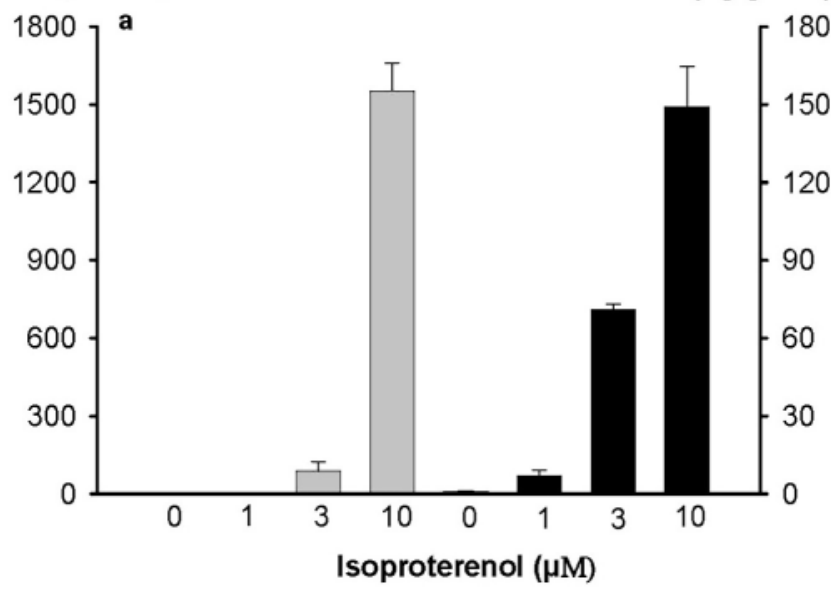

Fig. 2. Effects of adrenergic agonists on pineal AA-NAT activity (grey bars) and melatonin release (black bars) in incubated Siberian hamster pineal glands. a Pineal glands were incubated with increasing doses of the $\beta$-adrenergic agonist ISO for $5 \mathrm{~h}$. b Pineal glands were incubated with either no drug, $10 \mu M$ of the $\alpha$-adrenergic agonist PHE, $3 \mu M$ ISO or both $3 \mu M$ ISO plus $10 \mu M$ PHE for $5 \mathrm{~h}$. Pineal glands were collected $4 \mathrm{~h}$ after lights on, incubated for $2 \mathrm{~h}$ prior to treatment and then transferred to fresh medium containing the indicated treatment for $5 \mathrm{~h}$. AA-NAT activity was measured in each pineal gland immediately at the end of the experiment. Melatonin was assayed in the culture medium. Values are expressed as the mean \pm SEM of $n=4$ pineal glands (a) or $n=4$ independent cultures $(\mathbf{b}){ }^{*} \mathrm{p}<0.05$ when comparing ISO effect with/without PHE.

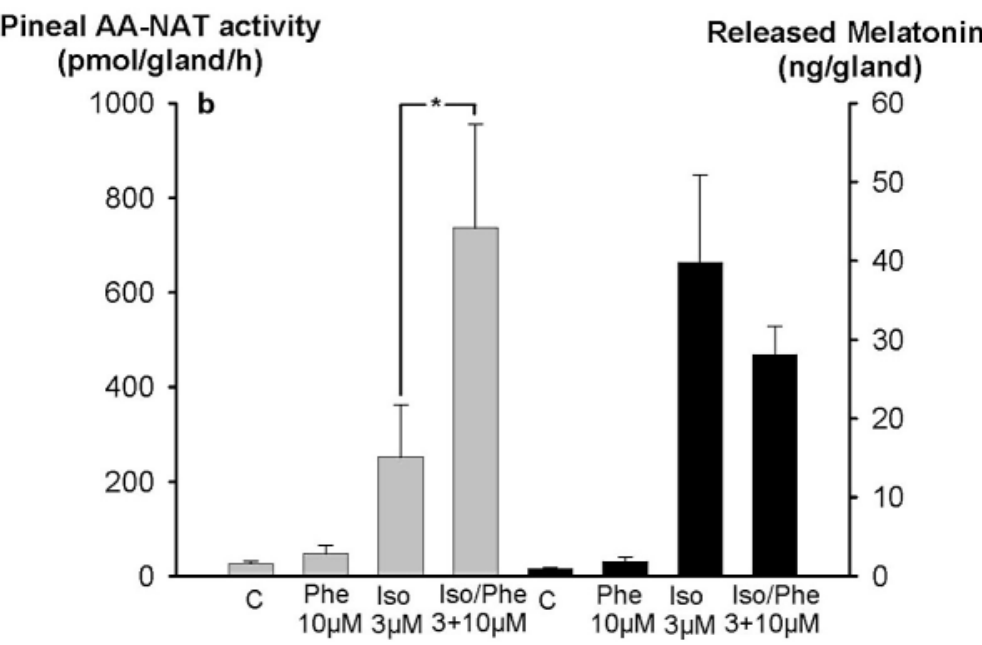


Fig. 3. Effect of the $\beta$-adrenergic agonist ISO on HIOMT activity in the Siberian hamster pineal gland. Pineal glands were collected $4 \mathrm{~h}$ after lights on, incubated for $2 \mathrm{~h}$ prior to treatment and then transferred to fresh medium. a For the short-term experiment, the pineal glands were incubated with $10 \mu M$ of the $\beta$-adrenergic agonist ISO or no drug for $5 \mathrm{~h}$, and HIOMT activity was measured in the tissue. b For the long-term experiment, the pineal glands were treated every day with $10 \mu M$ ISO or no drug for 5 days; HIOMT activity was measured in each gland at the end of the experiment. Values are expressed as the mean \pm SEM of $n=4$ pineal glands in one culture. ${ }^{*} \mathrm{p}<0.05$ as compared to control value. This experiment was performed three times with similar results.

\section{Pineal HIOMT activity \\ (pmol/gland/h)}

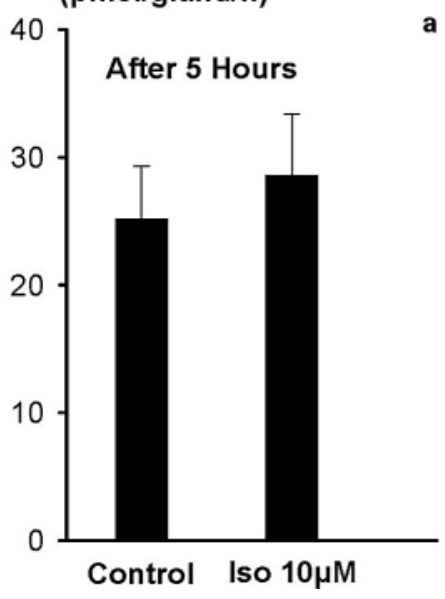

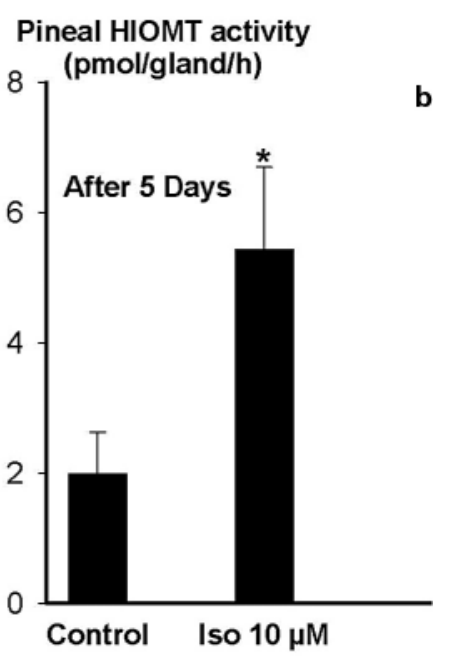

melatonin secretion in Siberian hamster pineal glands, $\beta$ and/or $\alpha$-adrenergic agonists were tested on incubated glands. Increasing doses of the $\beta$-adrenergic agonist ISO applied for $5 \mathrm{~h}$ induced a dose-dependent stimulation of AA-NAT activity and melatonin release (fig. 2a). Notably, increasing ISO concentrations from 3 to $10 \mu M$ enhanced AA-NAT activity by 10 -fold whereas augmentation of melatonin production was limited to 2-fold. Incubation of pineal glands with $10 \mu M$ of the $\alpha_{1}$-adrenergic PHE alone had no significant effect on AA-NAT activity or on melatonin secretion (fig. 2b). However, application of $10 \mu M$ PHE in combination with $3 \mu M$ ISO significantly enhanced AA-NAT activity, but this effect was not correlated with an increase in melatonin production (fig. 2b).

A 5-hour incubation with ISO, even at high doses, had no effect on pineal HIOMT activity (fig. 3a). Because HIOMT has been reported to be regulated on a long-term (days) rather than short-term (hours) range in rat pineal gland $[13,30]$, enzyme activity was compared in pineal glands kept for 5 consecutive days in culture with or without a chronic application of $10 \mu M$ ISO. HIOMT activity was significantly higher in ISO-incubated pineals as compared to no drug-incubated pineals (fig. 3b).

We then checked whether the long-term regulation of HIOMT could regulate the level of melatonin production independently of AA-NAT activity. The 5-day-long incubated pineal glands (with-high HIOMT activity - or without-low HIOMT activity $-10 \mu M$ ISO) were acutely (5 h) stimulated with $1 \mathrm{~m} M$ dbcAMP (dbcAMP was used instead of ISO to pass the AR that may not be in the same state in the two conditions). Five hours incubation of $1 \mathrm{~m} M$ dbcAMP induced a significant increase in AANAT activity and melatonin production but not HIOMT activity (fig. 4) whether the pineal glands were preincubated for 5 days with ISO or not, showing that the 5-day incubated pineal glands are still responsive to $\beta$-AR stimulation. As previously observed, the overall HIOMT activity was significantly higher after 5 days incubation with $10 \mu M$ ISO than without ISO. Importantly, the acute dbcAMP incubation induced a similar increase in AANAT activity in both conditions whereas the increase in melatonin production was higher in $10 \mu M$ ISO preincubated pineal glands, indicating that the higher HIOMT activity may drive a higher level of melatonin production.

\section{Adrenergic Regulation of Melatonin Synthesis in vivo}

In vitro experiments were indicative of an $\alpha$-adrenergic potentiation of $\beta$-adrenergic stimulation of AA-NAT activity but not of melatonin production in the Siberian hamster pineal gland. To further examine in vivo whether AA-NAT activity is regulated by either or both $\alpha$ - and $\beta$ AR, hamsters were treated with ISO, PHE or both during daytime. The $\beta$-adrenergic agonist ISO alone caused a highly significant increase in AA-NAT activity and melatonin content in the pineal gland of hamsters as compared to vehicle-treated animals (fig. 5). The specific $\alpha$-adrener- 
Fig. 4. Effect of an acute ( $5 \mathrm{~h})$ dbcAMP stimulation on Siberian hamster pineal gland pre-incubated for 5 days with or without $10 \mu M$ ISO. Pineal glands were collected $4 \mathrm{~h}$ after lights on, incubated for $2 \mathrm{~h}$ prior to treatment and then transferred to fresh medium. The pineal glands were treated every day with $10 \mu M$ ISO or no drug for 5 days. At the end of the long term incubation, pineal glands were acutely stimulated with $1 \mathrm{~m} M$ dbcAMP or not for $5 \mathrm{~h}$. Immediately after the treatment, pineal glands were assayed for AA-NAT and HIOMT activities and melatonin production was measured in the medium. Values are expressed as the mean \pm SEM of $n=4$ pineal glands in one culture. $* p<0.05$ when comparing the effect of dbcAMP between pineals preincubated with $10 \mu M$ ISO or not.
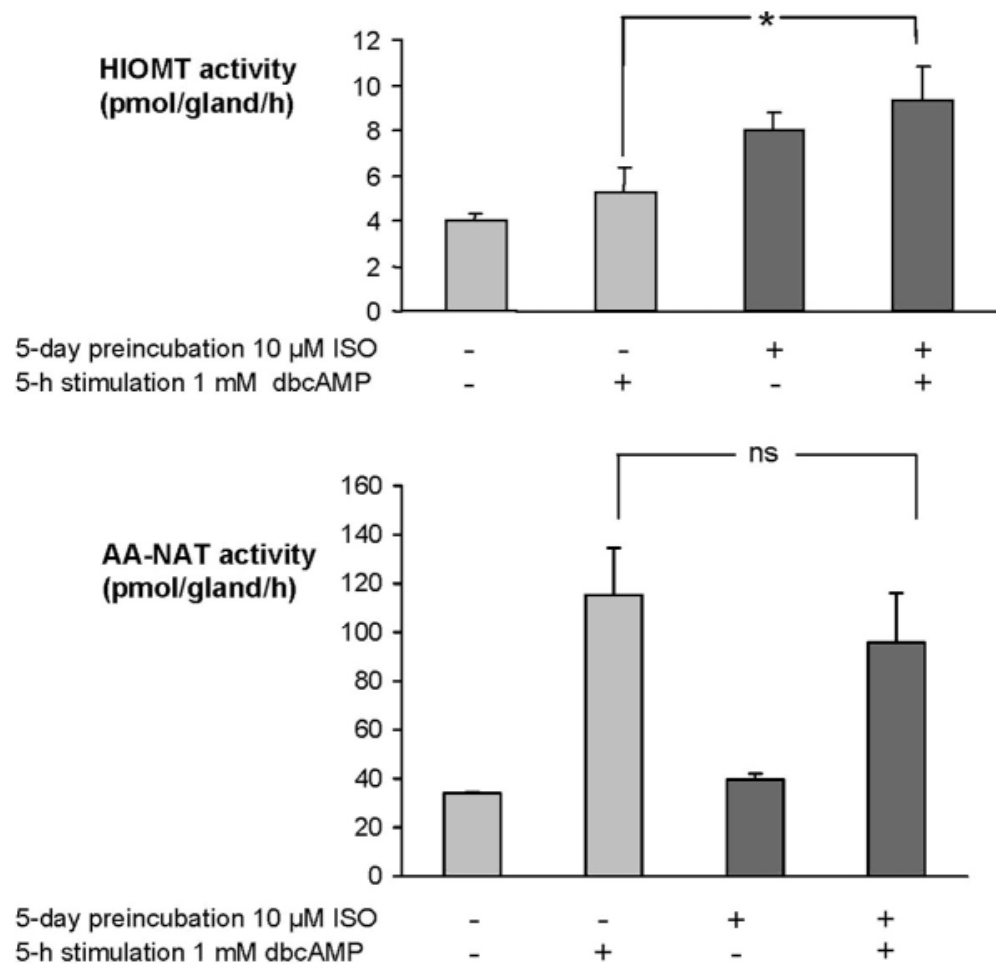

5-h stimulation $1 \mathrm{mM}$ dbcAMP

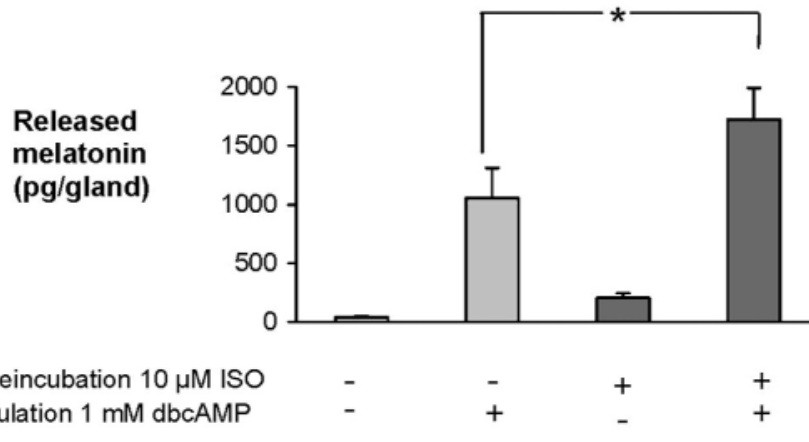

gic agonist PHE, although having no effect alone, significantly potentiated the ISO-induced AA-NAT activation (fig. 5). As observed in in vitro conditions, the $\alpha$-adrenergic potentiation of AA-NAT activity was not accompanied by a significant increase in pineal melatonin content.

To determine how AA-NAT activity and melatonin synthesis are regulated in vivo by NE during the night, the effect of night-time injection of the $\beta$-adrenergic antagonist PROP and the $\alpha$-adrenergic antagonist PRAZ were examined. PROP completely abolished nocturnal activation of AA-NAT and melatonin synthesis down to daytime values (fig. 6). PRAZ significantly reduced AA-NAT activity by about 5-fold, confirming the potentiating effect of $\alpha$-AR on enzyme activation. However, consistent with the previous experiments, PRAZ tended to reduce melatonin content although not to significantly (fig. 6). 
Fig. 5. Daytime regulation of AA-NAT activity and melatonin synthesis by adrenergic agonists in the Siberian hamster pineal gland. Hamsters were injected i.p. at $11 \mathrm{~h}$ either with vehicle (Ringer), the $\beta$-adrenergic agonist ISO $(5 \mathrm{mg} / \mathrm{kg})$, the $\alpha$-adrenergic agonist PHE $(5 \mathrm{mg} / \mathrm{kg})$ or both ISO $(5 \mathrm{mg} / \mathrm{kg})$ plus PHE $(5 \mathrm{mg} / \mathrm{kg})$. Animals were sacrificed $3 \mathrm{~h}$ after injection, and both AA-NAT activity (grey bars) and melatonin (black bars) were assayed in each pineal gland. Each point is the mean \pm SEM of $n=5$ glands. $* \mathrm{p}<0.05$ when comparing ISO effect with/ without PHE.

Fig. 6. Nighttime regulation of AA-NAT activity and melatonin synthesis by adrenergic antagonists in the Siberian hamster pineal gland. Hamsters were injected i.p. at $23 \mathrm{~h}$ with either vehicle (25\% dimethylsulfoxide in Ringer), the $\beta$-adrenergic antagonist propanolol (PROP, $20 \mathrm{mg} / \mathrm{kg}$ ) or the $\alpha$-adrenergic antagonist prazosine (PRAZ, $20 \mathrm{mg} / \mathrm{kg}$ ) and sacrificed $3 \mathrm{~h}$ after injection $(2 \mathrm{~h})$. At $11 \mathrm{~h}$ one group of untreated hamsters was used as a daytime value (C). Both AA-NAT activity (grey bars) and melatonin (black bars) were assayed in each pineal gland. Each point is the mean \pm SEM of $n=5$ glands. $* \mathrm{p}<0.05$ when comparing the effect of PRAZ with vehicle or PROP.
Pineal AA-NAT activity (pmol/gland/h)
Pineal melatonin (ng/gland)
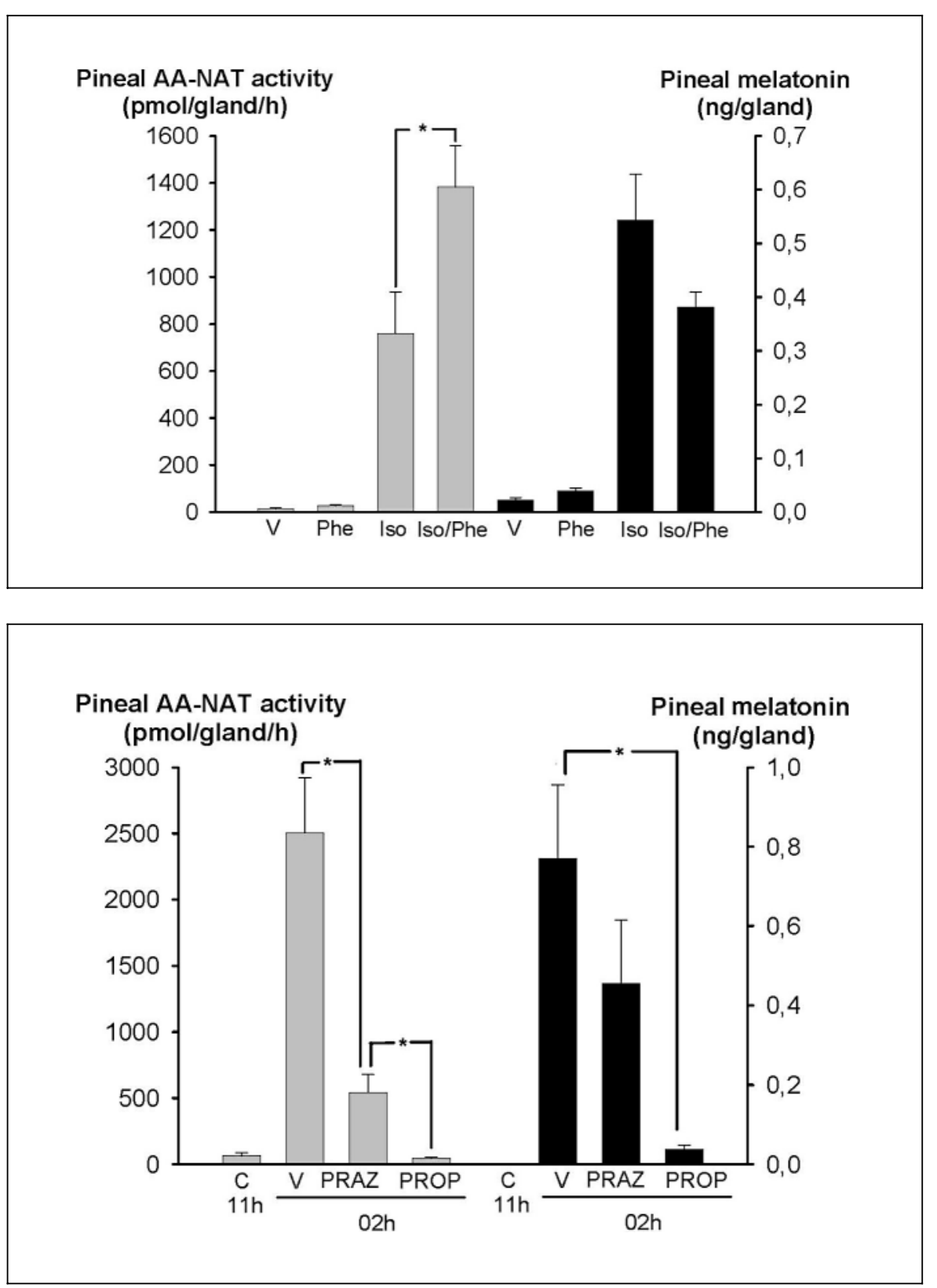

\section{Discussion}

Besides the laboratory rat model, few analyses of melatonin regulation have been performed in other rodents, especially in seasonal species [4 for review], despite the well-described role of melatonin in seasonal functions [13]. We chose to study melatonin synthesis in the Siberian hamster because this species displays high photoperiodic variations in duration and amplitude of the nocturnal melatonin peak [24-26].
Both in vivo and in vitro experiments confirmed the previous report in Siberian hamster that norepinephrine is the nocturnal transmitter for melatonin synthesis [27]. In the present study, the use of selective adrenergic agonists and antagonists allowed us to test the involvement of two adrenoceptor subtypes in the nocturnal stimulation of melatonin synthesis. The results show that (1) activation of $\beta$-AR is necessary and sufficient to induce melatonin synthesis, and (2) activation of $\alpha$-AR potentiates the $\beta$-AR stimulation of AA-NAT activity but not melatonin syn- 
thesis, thereby indicating a downstream limitation of the rate of melatonin, most probably at the level of HIOMT.

Both in vivo and in vitro, AA-NAT was highly sensitive to $\beta$-adrenergic stimulation, since enzyme activity could be increased by more than 100 -fold within a few hours. This activation depends, as observed in other rodents, on an acute stimulation of Aa-nat gene expression. HIOMT activity in contrast is not increased following a few hours of adrenergic stimulation, which is in good agreement with our previous in vivo experiments showing a constant elevated HIOMT activity throughout the 24hour cycle [26]. In Siberian hamster, as in the rat, therefore, the nocturnal increase in melatonin production depends on a strong AA-NAT activation while HIOMT activity remains constantly elevated.

Previous experiments performed in the rat pineal gland have shown that $\beta$-AR stimulation of AA-NAT activity could be further enhanced by a concomitant activation of $\alpha-\mathrm{AR}$ via a potentiation of cAMP production $[10,18]$. In the Siberian hamster as well, our experiments show that the $\alpha$ AR agonist PHE has no effect per se on AA-NAT activity, but enhances the $\beta$-AR activation of AA-NAT both in vitro and in vivo. Furthermore, administration of the $\alpha$-AR antagonist PRAZ during the night significantly reduced by about 5-fold AA-NAT activity, indicating that the endogenous NE acts on both $\alpha$ - and $\beta$-AR to fully activate AA-NAT.

Notably, the $\alpha$-AR potentiation of $\beta$-AR stimulation of AA-NAT activity was not accompanied by a similar enhancement of melatonin production. In vitro and in vivo, PHE administration significantly enhanced ISOinduced stimulation of AA-NAT activity but not of melatonin synthesis and release. This result indicates that the elevation of AA-NAT activity was sufficient for a maximal melatonin synthesis, and therefore a larger increase in AA-NAT activity, following the $\alpha$-AR potentiation, fails to induce a larger increase in melatonin synthesis. This is in agreement with the data obtained with the dose-dependent effect of ISO showing a larger effect of ISO on AANAT activity than on melatonin release. Because the exogenous $\beta$-AR agonist may be too strong and stable to allow a subtle $\alpha$-AR potentiation of melatonin synthesis, the effect of an $\alpha$-AR antagonist, PRAZ, on the endogenous NE-induced melatonin synthesis was analyzed in vivo. Whereas PRAZ injection strongly reduced nighttime AA-NAT activity by about 5-fold, melatonin content was slightly reduced with no statistical significance. To our knowledge, such differential effects of $\alpha$ - and $\beta$-AR regulation on AA-NAT activity and melatonin production have never been reported in the rat pineal gland. It would be interesting to examine whether this differential regulation is limited to the Siberian hamster or is a boarder phenomenon in seasonal mammals.

These observations strongly support the concept that, although initiated by AA-NAT activation, the rate (amplitude) of melatonin production in the Siberian hamster pineal gland does not depend on the level of AA-NAT activity. This concept might be extended to other species like the rat [14] or the Syrian hamster [29] for which in vivo variations in AA-NAT gene expression and activity are not paralleled by similar variations in melatonin synthesis.

Based on several lines of indirect evidence, we propose that the rate of melatonin production, once initiated by AA-NAT activation, is limited by the level of HIOMT activity. This hypothesis implies that, even at high AANAT activity, any change in HIOMT activity would result in a similar modification of melatonin production. We previously examined the regulation of HIOMT gene expression and activity in the rat pineal gland [13, 14, 30]. We reported that the levels of pineal HIOMT mRNA and activity are high throughout the 24-hour cycle. The nocturnal release of NE further increased HIOMT mRNA level, but had no acute effect on HIOMT activity. This discrepancy is thought to result from the high stability of HIOMT protein. The half-life of HIOMT protein being longer than $24 \mathrm{~h}$ [31] likely implies that the small nocturnal increase in HIOMT transcript does not affect HIOMT activity on a daily basis but rather on a long term. This hypothesis was confirmed in vitro where rat pinealocytes cultured for up to 10 days with chronic ISO stimulation exhibited higher HIOMT activity than rat pinealocytes cultured without adrenergic stimulation [30]. Interestingly, we report here that HIOMT activity in the Siberian hamster pineal is also regulated on a long term basis. Enzyme activity in cultured pineal glands is not modified following $5 \mathrm{~h}$ incubation with ISO. By contrast, repeated applications of ISO for 5 days keep HIOMT activity at a higher level compared to pineal glands incubated without adrenergic agonist. Strikingly, in this experimental condition, an acute stimulation with dbcAMP induces a similar increase in AA-NAT activity but a higher production of melatonin in relation with higher HIOMT activity.

As a consequence of the long-term adrenergic regulation of HIOMT activity, we hypothesized that in short photoperiod, when night length and pineal adrenergic stimulation is longer, HIOMT activity should be higher than in long photoperiod. In the rat, we confirmed that under short photoperiod the increase in nighttime dura- 
tion induced a similar increase in the duration of the nocturnal peak of the Hiomt transcript and consequently an increase in the daily level of HIOMT activity [14]. Similarly, in the Siberian hamster a 2-fold increase in HIOMT activity over the 24-hour cycle was observed in short as compared to long photoperiod [26]. Strikingly, the melatonin peak amplitude in this species is also twice as high in short as compared with long photoperiod. This observation must be associated with the increase in HIOMT activity and not with AA-NAT activity because, by contrast, nighttime AA-NAT activity is twice lower in short photoperiod [24, 26]. These previous observations, together with the present finding that the rate of melatonin production is not limited by the level of AA-NAT activity, strengthen the hypothesis that HIOMT activity 'tunes' the rate of melatonin production, with photoperiodic variation.

The regulation of HIOMT gene expression and activity at daily and seasonal scales is far from being understood. $\mathrm{NE}$ is obviously involved in the nocturnal increase of
Hiomt mRNA in the rat, which in turn induces a long term/photoperiodic regulation of HIOMT activity, but nothing is known about the mechanisms maintaining a high constitutive level of HIOMT gene expression and enzyme activity over the 24-hour cycle. Moreover, neuropeptide $\mathrm{Y}$, a neuropeptide co-localized with NE in the sympathetic terminals, is thought to regulate HIOMT activity in the rat [30] and European hamster [32] pineal gland. Investigations on the daily/seasonal regulation of HIOMT gene expression and enzyme activity by various transmitters will now be performed in the Siberian hamster to reveal the mechanisms underlying seasonal regulation of melatonin synthesis.

\section{Acknowledgements}

Authors are grateful to Dr. M.T. Romero for the English correction of the manuscript.

\section{References}

1 Reiter RJ: The melatonin rhythm: Both a clock and a calendar. Experientia 1993;49:654-664.

$>2$ Bartness TJ, Powers JB, Hastings MH, Bittman EL, Goldman BD: The time infusion paradigm for melatonin delivery: What has it taught us about the melatonin signal, its perception, and the photoperiodic control of seasonal responses? J Pineal Res 1993;15:161190.

>3 Goldman BD: Mammalian photoperiodic system: formal properties and neuroendocrine mechanisms of photoperiodic time measurement. J Biol Rhythms 2001;16:283-301.

$\checkmark 4$ Simonneaux V, Ribelayga C: Generation of the melatonin endocrine message in mammals: A review of the complex regulation of melatonin synthesis by norepinephrine, peptides, and other pineal transmitters. Pharmacol Rev 2003; 55:325-395.

$\checkmark 5$ Kappers JA: The development, topographical relations and innervation of the epiphysis cerebri in the albino rat. Z Zellforsch 1960;52:163215.

6 Klein DC, Moore RY: Pineal $N$-acetyltransferase and hydroxyindole-O-methyltransferase: Control by the retinohypothalamic tract and the suprachiasmatic nucleus. Brain Res 1979; 174:245-262.

7 Larsen PJ: Tracing autonomic innervation of the rat pineal gland using viral transneuronal tracing. Microsc Res Tech 1999;46:296-304.
$>$ Drijfhout WJ, van der Linde AG, Kooi SE, Grol CJ, Westerink BHC: Norepinephrine release in the rat pineal gland: The input from the biological clock measured by in vivo microdialysis pathetic inhibition of pineal indole metabolism by prejuctional modulation of noradrenaline release. J Neurochem 1996;66:748755.

9 Axelrod J: The pineal gland: A neurochemical transducter. Science 1974;184:134-148.

10 Klein DC: Photoneural regulation of the mammalian pineal gland; in Everet D, Clark D (eds): Photoperiodism, Melatonin and the Pineal. Ciba Foundation Symposium. London, Pitman, 1985, pp 38-56.

11 King TS, Steinlechner S: Pineal indolalkylamine synthesis and metabolism: Kinetic considerations. Pineal Res Rev 1985;3:69-113.

12 Klein DC, Coon SL, Roseboom PH, Weller JL, Bernard M, Gastel JA, Zatz M, Iuvone PM, Rodriguez IR, Bégay V, Falcon J, Cahill GM, Cassone VM, Baler R: The melatonin rhythmgenerating enzyme: molecular regulation of serotonin $\mathrm{N}$-acetyltransferase in the pineal gland. Rec Prog Horm Res 1997;52:307-358.

13 Ribelayga C, Gauer F, Calgari C, Pévet P, Simonneaux V: Photoneural regulation of rat pineal hydroxyindole-O-methyltransferase (HIOMT) messenger ribonucleic acid expression: An analysis of its complex relationship with HIOMT activity. Endocrinology 1999; 140:1375-1384.
14 Ribelayga C, Garidou ML, Malan A, Gauer F, Calgari C, Pévet P, Simonneaux V: Photoperiodic control of the rat pineal arylalkylamine$\mathrm{N}$-acetyltransferase and hydroxyindole-Omethyltransferase gene expression and its consequence on melatonin synthesis. $\mathrm{J}$ Biol Rhythms 1999;14:105-115.

15 Klein DC, Ganguly S, Coon SL, Shi Q, Gaildrat P, Morin F, Weller JL, Obsil T, Hickman A, Dyda F: $14-3-3$ proteins in pineal photoneuroendocrine transduction: How many roles? J Neuroendocrinol 2003;15:370-377.

16 Gauer F, Craft CM: Circadian regulation of hydroxyindole-O-methyltransferase mRNA levels in rat pineal retina. Brain Res 1996;737: 99-109.

17 Sugden L, Sugden D, Klein DC: $\alpha_{1}$-Adrenoceptor activation elevates cytosolic calcium in rat pinealocytes by increasing net influx. J Biol Chem 1987;262:741-745.

18 Vanecek J, Sugden D, Weller JL, Klein DC: Atypical synergistic $\alpha_{1}$ - and $\beta$-adrenergic regulation of adenosine $3^{\prime}, 5^{\prime}$-monophosphate and guanosine $3^{\prime}, 5^{\prime}$-monophosphate in rat pinealocytes. Endocrinology 1985;116:2167-2173.

19 Chik CL, Ho AK: Multiple receptor regulation of cyclic nucleotides in rat pinealocytes. Prog Biophys Mol Biol 1989;53:197-203.

20 Simonneaux V, Garidou ML, Ribelayga C, Pévet P: Mechanisms underlying seasonal regulation of melatonin synthesis in rodents; in Cardinali D (ed): In press. 
21 Carter DS, Goldman BD: Antigonadal effects of timed melatonin infusion in pinealectomized male Djungarian hamsters (Phodopus sungorus sungorus): Duration is the critical parameter. Endocrinology 1983;113:1261-1267.

22 Pitrosky B, Masson-Pévet M, Kirsch R, Vivien-Roels B, Canguilhem B, Pévet P: Effects of different doses and durations of melatonin infusions on plasma melatonin concentrations in pinealectomized Syrian hamster: Consequences at the level of sexual activity. J Pineal Res 1991;11:149-155.

23 Vivien-Roels B: Seasonal variations in the amplitude of the daily pattern of melatonin secretion in mammalian and non-mammalian vertebrates: Possible physiological consequences; in Joy KP, Krishna A, Haldar C (eds): Comparative Endocrinology and Mammalian Reproduction Physiology. New Delhi, Narosa Pub House, 1999, pp 529-542.

24 Illnerova H, Hoffmann K, Vanecek J: Adjustment of pineal melatonin and $N$-acetyltransferase rhythms to change from long to short photoperiod in the Djungarian hamster Phodopus sungorus. Neuroendocrinology 1984;38:321326.
25 Míguez RM, Recio J, Vivien-Roels B, Pévet P: Diurnal changes in the content of indoleamines, catecholamines, and methoxyindoles in the pineal gland of the Siberian hamster (Phodopus sungorus): Effect of photoperiod. J Pineal Res 1996;21:7-14.

26 Ribelayga C, Pévet P, Simonneaux V: HIOMT drives the photoperiodic changes in the amplitude of the melatonin peak of the Siberian hamster. Am J Physiol 2000;278:R1339R1345.

-27 Steinlechner S, King TS, Champney TH, Spanel-Borowski K, Reiter RJ: Comparison of the effects of beta-adrenergic agents on pineal serotonin $\mathrm{N}$-acetyltransferase activity and melatonin content in two species of hamsters. J Pineal Res 1984;1:23-30.

28 Garidou ML, Bartol I, Calgari C, Pévet P, Simonneaux V: In vivo observation of a nonnoradrenergic regulation of arylalkylamine Nacetyltransferase gene expression in the rat pineal complex. Neuroscience 2001;105:721729.
29 Garidou ML, Diaz E, Calgari C, Pévet P, Simonneaux V: Transcription factors may frame Aa-nat gene expression and melatonin synthesis at night in the Syrian hamster pineal gland. Endocrinology 2003;144:2461-2472.

30 Ribelayga C, Pévet P, Simonneaux V: Adrenergic and peptidergic regulations of hydroxyindole-O-methyltransferase in rat pineal gland. Brain Res 1997;777:247-250.

31 Bernard M, Guerlotte J, Cogne M, Greve P, Collin JP, Voisin P: Transcriptional regulation of hydroxyindole-O-methyltransferase in the chicken pineal gland: Day/night changes and long-term effects of light and darkness. Biochem J 1993;290:661-664.

32 Ribelayga C, Pévet P, Simonneaux V: Possible involvement of neuropeptide $\mathrm{Y}$ in the seasonal control of hydroxyindole-O-methyltransferase in the pineal gland of the European hamster (Cricetus cricetus). Brain Res 1998;801:137142. 